\title{
Effect of zinc injection on the corrosion products in nuclear fuel assembly
}

\author{
Jin-Soo Choi ${ }^{{ }^{*}}$, Seung-Chul Park ${ }^{1}$, Kyoung-Rok Park ${ }^{1}$, Ho-Yeon Yang ${ }^{1}$, O-Bong Yang ${ }^{2}$ \\ ${ }^{1}$ KHNP-Central Research Institute, Korea Hydro \& Nuclear Power Corporation, Daejeon, South Korea; \\ *Corresponding Author: feliz@,khnp.co.kr \\ ${ }^{2}$ School of Chemical Engineering, Chonbuk National University, Jeonju, South Korea
}

Received 14 November 2012; revised 15 December 2012; accepted 30 December 2012

\section{ABSTRACT}

The accumulation of corrosive and radioactive wastes in the primary system, including nuclear fuel assembly, significantly increases workers' exposure to radiation. Zinc injection from 5 to $\mathbf{4 0}$ ppb into the Reactor Coolant System (RCS) of Pressurized Water Reactors (PWRs) has been known as an effective method to decrease the radiation fields and Primary Water Stress Corrosion Cracking (PWSCC). Zinc injection affects both corrosion product concentrations and characteristics of the deposited crud on oxide layers, because zinc is incorporated into the oxide films by displacing nickel, cobalt, and iron in primary systems. Radiation fields and corrosion might be mitigated as radioactive products, such as Co, which are removed by zinc injection. However, the zinc injection effects on fuel assembly in Nuclear Power Plants (NPPs) have not been much reported yet, even though some lab tests were carried out in USA and France. In this paper, we studied effects of zinc injection on the fuel assemblies in the Ulchin 1 NPP. The chemical and radiation analysis of radioactive corrosion products was performed to evaluate zinc injection effects on the fuel assembly in the Ulchin 1 NPP. Gamma spectroscopy was used to analyze crud samples for radioisotope contents. The Inductively Coupled Plasma-Atomic Emission Spectrometry (ICP-AES) was used to analyze crud samples for elemental contents. The concentration of radioisotope Co-58 was decreased after zinc injection to $1 / 22$ times that before the zinc injection. $1 \%-2 \% \mathrm{wt} \%$ of zinc was incorporated through the substitution of $\mathrm{Ni}$ in the crud oxide layer. The Ni/Fe ratio was decreased to 0.69 from 1.12 after the injection, due to the Ni substitution by zinc. It was found that $\mathrm{NiO}$ and $\mathrm{NiFe}_{2} \mathrm{O}_{4}$ were converted to $\mathrm{ZnO}$ and $\mathrm{ZnFe}_{2} \mathrm{O}_{4}$, respectively. In conclusion, zinc injec- tion was found to be an essential method to reduce the amount of radioactive Co-58 in the fuel assemblies of primary systems in NPPs.

Keywords: Zinc Injection; Dose Rates; PWSCC; RCS; Oxide Layers

\section{INTRODUCTION}

Recently the necessity of reducing operators' exposure to radiation has been raised as the radiation doses are being increased due to the accumulation of radioactive materials in the various plant systems along with the increase of the years of nuclear power plant operation. The zinc injection into the reactor coolants is the technology to reduce radiation fields and corrosion in the primary system. It was first applied to Farley Unit 2 in the USA in mid 1994 and since then has been applied to $76 \mathrm{nu}-$ clear power plants, which make up $29 \%$ of the total number of light water reactors overseas [1-4].

Zinc has the characteristics of changing the ingredients of the corrosion oxide layers of the primary systems to a stable state by causing a discharge of the radioactive products $(\mathrm{Ni}, \mathrm{Fe}, \mathrm{Co}$ etc.) that exist in the oxide layers and substituting them, which is possible due to its higher substitution energy [5-7].

Thus, injecting a very small quantity of zinc (5 - 40 $\mathrm{ppb}$ ) shows the effects of not only reducing radioactivity by the removal of radioactive materials and the formation of stable oxide layers but also enhances the anticorrosion properties of materials. To utilize such characteristics, a low concentration of zinc is applied for radioactivity reduction and a high concentration is applied for corrosion reduction $[2,3]$.

The integrity of nuclear fuel cladding is one of the top priorities for plant safety and is also important for the wider adoption of zinc injection operations. For this purpose, a safety evaluation of nuclear fuels for all the nuclear power plants in Korea was carried out, during which samples of fuel cladding oxide layer crud were 
taken and analyzed. Through this an abundant quantity of information and knowledge has been accumulated, but it is not sufficient yet for a quantitative analysis of the crud behaviors and operation parameters.

In Korea, the first adoption of zinc injections was made at Ulchin 1, in 2010, for the purpose of radiation reduction and corrosion mitigation. Although the first application took place, there had not been any studies on the effects of the zinc injection on nuclear fuel oxide layers and thus there was no primary data, which is needed for the evaluation of the effects of the initial zinc injection on the nuclear fuel claddings. Especially the Ulchin 1 has twice experienced the Axial Offset Anomaly (AOA), which is a phenomenon of an axial output unbalance of nuclear fuels due to corrosion products [8]. Data from analyzing oxide layers following zinc injection, especially for the plants, including overseas, having the experiences of AOA is very few. Hence, the acknowledgement is the need for a study of the evaluation of the impacts of zinc injection for radioactivity reduction and corrosion mitigation on the oxide layers reformation. This can be achieved by implementing the analysis of the oxide layers of the nuclear fuel claddings of the Ulchin 1 that have undergone of zinc injection.

Thus, in this paper, an evaluation of the impacts of the zinc injection on the oxide layers of the primary systems of nuclear power plants is implemented by way of radioactivity and chemical contents analysis of the fuel cleaning crud of Ulchin 1. Samples of the oxide layers of fuel claddings are taken by ultrasonic fuel cleaning. For the evaluation of zinc injection effects, the HPGe gamma nuclide analyzer (HPGe GEM 30185-P, EG\&G ORTEC) is used for radioactivity analysis and the Inductively Coupled Plasma-Atomic Emission Spectrometry (IRIS HR, THERMO JARREL ASH) is used for chemical contents analysis.

\section{OXIDE LAYERS OF FUEL CLADDINGS AND ZINC SUBSTITUTION}

The studies on nuclear fuel crud taken from nuclear fuels have been actively done by many with Studsvik, which is a supplier of nuclear analysis software of Sweden that plays the key role of study Crud is metal oxide mainly consisting of iron, nickel, and chrome. It is known that the main constituents of nuclear fuel cladding oxide layers for PWR fuels are nonstoichiometric nickel ferrite $\left(\mathrm{Ni}_{\mathrm{x}} \mathrm{Fe}_{3-\mathrm{x}} \mathrm{O}_{4}\right)$ and $\mathrm{NiO}[9,10]$. Due to low cobalt content and the activation of nickel to $\mathrm{Co}$, it appears as $\mathrm{Co}_{y} \mathrm{Ni}_{x} \mathrm{Fe}_{3-\mathrm{x}-\mathrm{y}} \mathrm{O}_{4}$, where $x+y=1(y \ll x)$. Generally, at all the power plants, $\mathrm{x}$ is apparently bigger than 1 and the excessive $\mathrm{Ni} / \mathrm{Fe}$ ratio, which is not possible stoichiometrically, is observed $[11,12]$.

Upon the injection of zinc in reactor coolant, which is across all of the oxide layers, active substitution reac- tions take place. The zinc is injected into the zinc acetate solution, as the state of zinc ion $\left(\mathrm{Zn}^{2+}\right)$. The zinc ion is a doubly charged ion and thus displaces doubly charged ions such as nickel, iron, cobalt, etc. in the spinel crystal structure. Nickel, iron, cobalt, etc. are thus eluted and zinc takes the position for binding. The filters and ion exchange resins remove the eluted corrosion products in the CVCS systems $[13,14]$.

Especially, the ferrite oxide layer, which is the outermost layer, is in contact with the coolant and thus most actively experiences the corrosion and at the same time the zinc substitution. Before the zinc injection, the oxide layer is irregular and has a considerable amount of particle type of corrosion products where corrosion is proceeding through active ion exchanges. But if zinc is injected, the oxide layer is reformed to the zinc oxide layer $\left(\mathrm{ZnFe}_{2} \mathrm{O}_{4}\right.$ or $\left.\mathrm{ZnCr}_{3} \mathrm{O}_{4}\right)$, which is thinner than before, and it prohibits the re-substitution of corrosion products such as $\mathrm{Co}$ and thus constitutes a stable oxide layer $[11,15]$.

\section{EXPERIMENT METHOD}

\subsection{Characteristics of Zinc and the Type of Zinc Injection}

$\mathrm{Zn}-64$, of which atomic weight is 64 , which is naturally found in zinc, has the natural existence ratio of $48.89 \%$, which is approximately half of the zinc that is naturally found. If the naturally found zinc is injected into the reactor coolant system, Zn-64 creates the isotope $\mathrm{Zn}-65$ upon the irradiation of neutrons in the reactor core. Therefore, nuclear power plants, where zinc injection is adopted, generally use depleted zinc having Zn-64 that has been reduced to less than $1 \%$. Considering this, Ulchin 1, where the main purpose of zinc injection is for radioactivity reduction, uses depleted zinc with the goal of keeping the concentration at $5 \mathrm{ppb}$. The type of zinc used for the zinc injection is zinc acetate $\left(\mathrm{C}_{4} \mathrm{H}_{10} \mathrm{O}_{6} \mathrm{Zn}\right)$ hydrate [16].

\subsection{Reactor Coolant Zinc Injection}

The zinc injection for Ulchin 1 was implemented during the cycle 17. As for the injection timing, the injection had started after 14 months since plant start-up, which was when the core output was expected to be stabilized, to minimize the core burden. The zinc injection started on April 19, 2010 and finished on October 25, 2010. The zinc solution was injected continuously during these 129 days. The rate of injection was $5-10 \mathrm{ml} / \mathrm{min}$ in volume, meaning a mass flow of $10-20 \mathrm{~g} /$ day and the total accumulated injected zinc reached $1.8 \mathrm{~kg}$.

The injection was made in the inlet of the charging pump of the Chemical and Volume Control System (CVCS). A special injection skid that was made in-house with a minute quantity-metering pump was used and the 
injection was made under a strict flow control (Figure 1).

\subsection{Selection of Crud Sampling Points}

To understand the substitution effects of zinc injections, four nuclear fuel assemblies were selected by considering the degree of oxide layer formation and the effects being exposed to zinc. For the selected set of fuel assemblies, the maximum period of operation (two core cycles) was implemented, and then the fuel assemblies that were deemed to have been the most exposed to an oxidation environment were selected. Table 1 shows data about the selected nuclear fuel assemblies.

\subsection{Crud Sampling and Transportation}

Subsequent to the commencement of zinc injection into the reactor coolant systems of Ulchin 1, during the refueling outage 16 , scheduled preventive maintenance period, the first crud ultrasonic cleaning for the 89 reloaded fuel assemblies for cycle 17 was implemented and a quantity of crud having a radioactivity $1200 \mathrm{R} / \mathrm{hr}$ and weighing $1340 \mathrm{~g}$, was removed.

Crud samples were taken, during ultrasonic cleaning, by use of the filtered material collector of the crud filter which is a built-in component of the ultrasonic cleaner (Figures 2 and $\mathbf{3}$ ).

The crud collector consists of two pumps, eight filter containers, an instrument for measuring temperature, pressure and flow, and radioactivity detectors that can monitor the process of crud removal and radioactivity during the crud cleaning (Figure 4). A sampler that can be used to take crud samples was also built in. For the actual crud removal, only one pump and four filtering devices are operated (Figures $\mathbf{4}$ and 5).
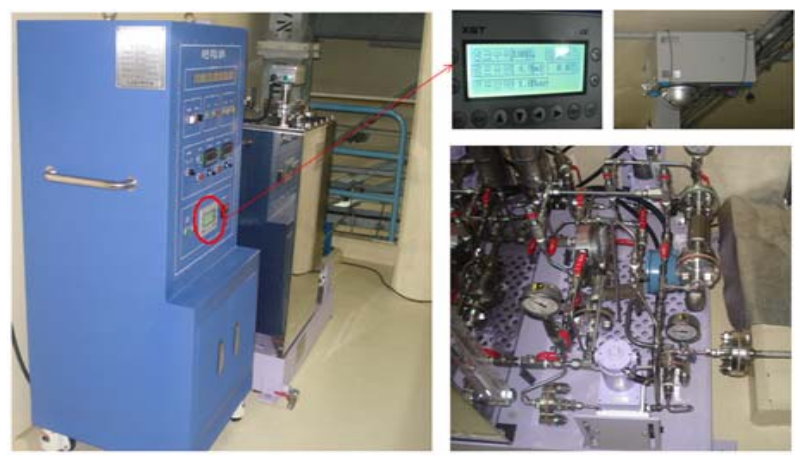

Figure 1. Ulchin 1 zinc injection skid.

Table 1. Crud sampling fuel assemblies.

\begin{tabular}{cccc}
\hline Classification & $\begin{array}{c}\text { Number } \\
\text { of Assemblies }\end{array}$ & $\begin{array}{c}\text { Fuel Assembly } \\
\text { Number }\end{array}$ & Remarks \\
\hline $\begin{array}{c}\text { Two cycles } \\
\text { Fuel burning }\end{array}$ & 4 & Q23, R19, & $\begin{array}{c}\text { Fuel rod for oxide layer } \\
\text { thickness measurement } \\
\text { and curd sampling }\end{array}$ \\
\hline
\end{tabular}

There were four samples collected, from the S64, Q23, S42, and R19, respectively. They were stored together with the filter cartridges. Figure 6 shows the process of disassembling the filter cartridges. Figure 7 shows the filters that are separately contained in beakers for preprocessing.

\section{RESULTS OF THE EXPERIMENT AND DISCUSSION}

\subsection{Preprocessing of Samples}

The radioactive crud samples collected from the filters contain a lot of moisture and thus drying was a mandate for radiochemical quantification. The weights of filters and radioactive crud were measured using the scale, which is only used for radioactive materials. The samples contained in beakers were put in the electric furnace and dried for 6 hours at the temperature of $110^{\circ} \mathrm{C}$ and then the weights were measured. The weights of the samples were measured 6 times and the weights of the dried samples are shown in Tables 2 and 3. Throughout the 6 measurements, the uncertainty of the weight measurement was found to be $0.002 \mathrm{~g}$. The weights of the samples fell in the range of $0.074-0.088 \mathrm{~g}$.

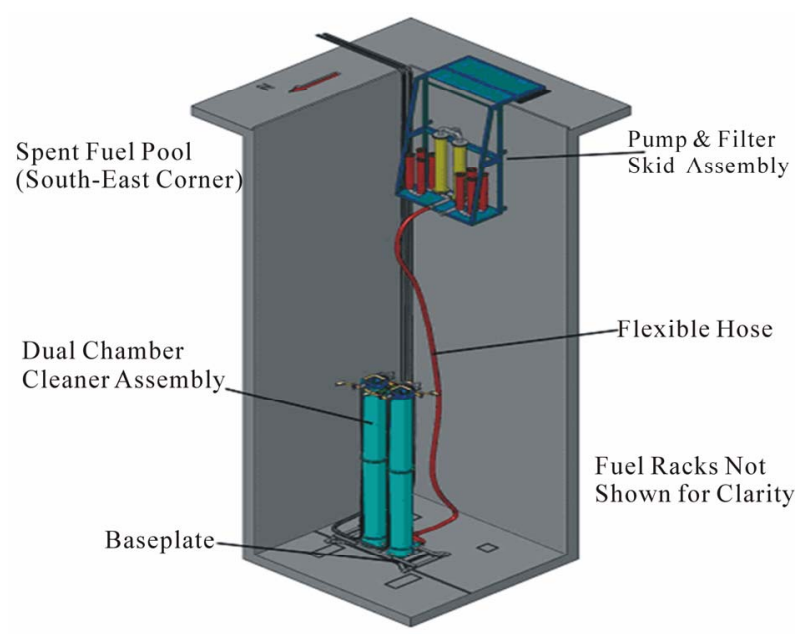

Figure 2. Simplified view of the ultrasonic crud removal device.

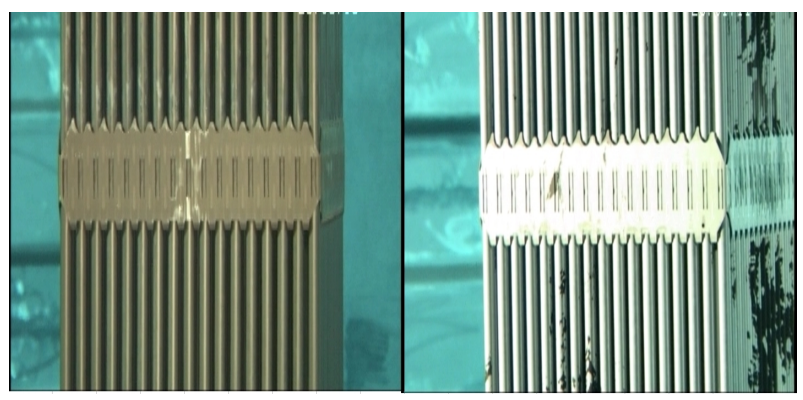

Figure 3. Fuel assembly R19-before (left) and after (right) crud removal. 


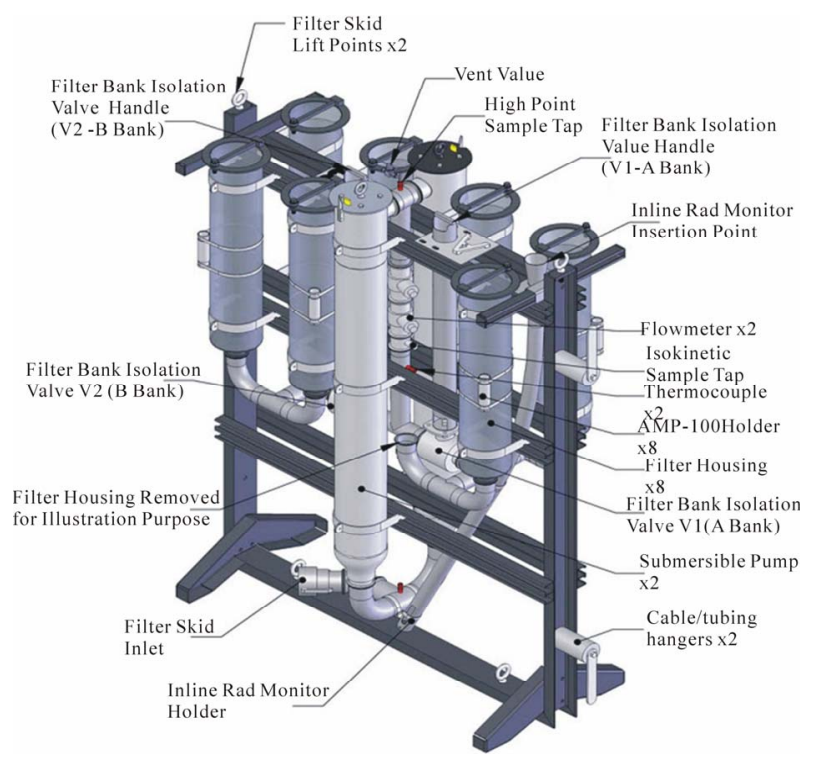

Figure 4. Collection filter device of crud removal equipment (collection pump and filter).

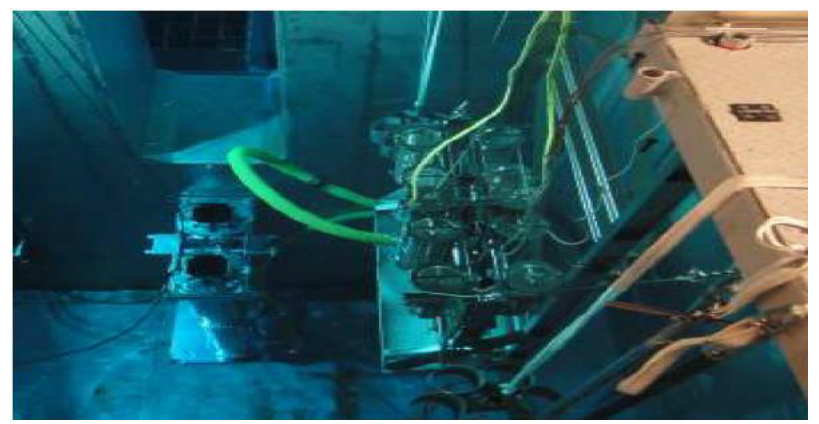

Figure 5. Ultrasonic cleaning equipment at Ulchin 1.

Since the quantities of samples were very small, the crud could not be separated from the filters and so, as shown in Figure 8, the crud samples and the filters were put together in the solution for the dissolution of the crud. $6 \mathrm{~mL}$ each of thick hydrochloric acid and nitric acid were added and warmed at a low temperature on a hot plate. 2 $\mathrm{mL}$ of HF was added and the heating process was continued. After the crud samples were completely dissolved, it was moved to the tube for centrifugation. Distilled water was added to adjust the volume to $40 \mathrm{~mL}$.

\subsection{Analysis of Chemical Constituents}

Chemical constituents were measured with dissolver solutions using the inductively coupled plasma atomic emission spectrometer (IRIS HR, THERMO JARREL ASH) which can be used for measuring the chemical compositions of radioactive samples.

The results of the analysis of crud constituents by ICP-AES showed, as listed in Tables 4-7, that the main elements constructing the nuclear fuel oxide layers were $\mathrm{Fe}, \mathrm{Ni}$, and $\mathrm{Zr}$. Considering that the main elements

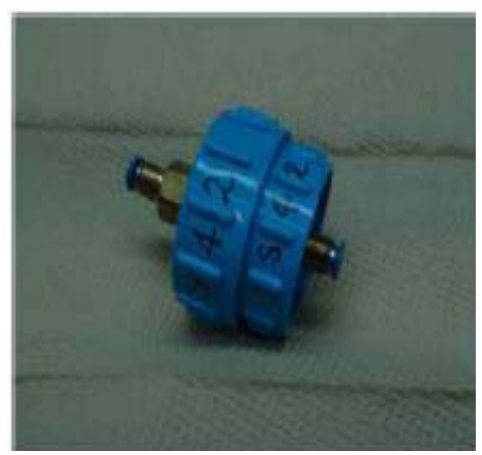

(a)

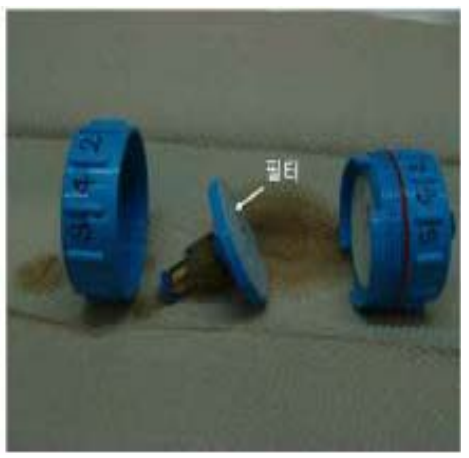

(b)

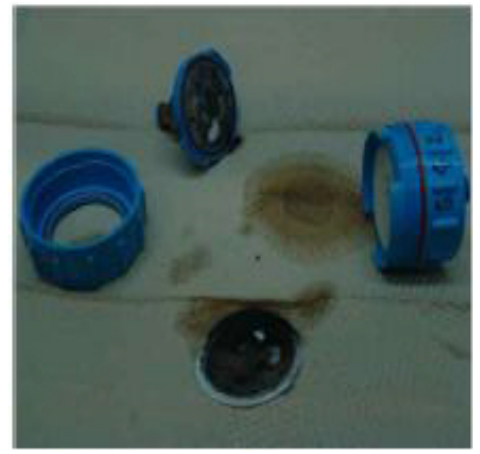

(c)

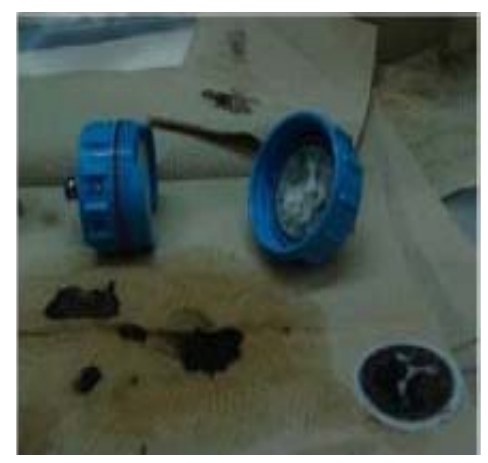

Figure 6. Process of detaching crud samples from filter cartridges. (a) Before cartridge disassembly; (b) After cartridge disassembly; (c) After cartridge detachment; (d) Solution and filter after cartridge detachment. 


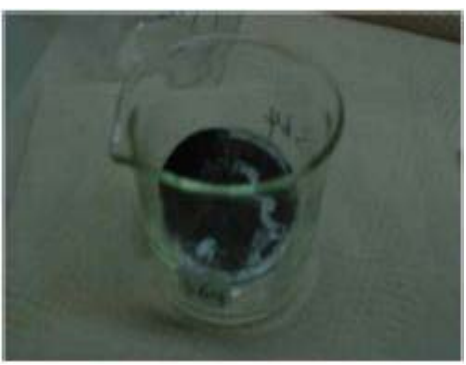

(a)

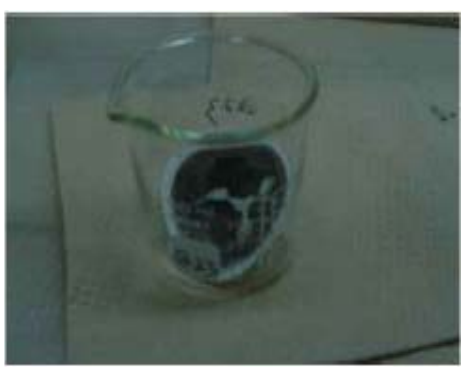

(b)

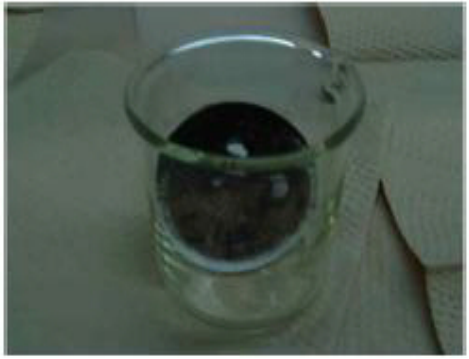

(c)

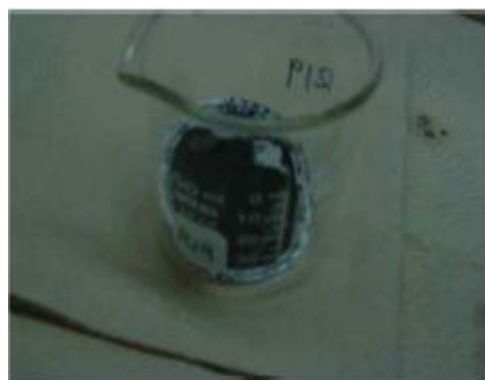

(d)

Figure 7. Filtered radioactive crud deposited on filters. (a) Crud on Filter (S64); (b) Crud on Filter (Q23); (c) Crud on Filter (S42); (d) Crud on Filter (R19).

Table 2. Weights of dried radioactive crud samples before zinc injection.

\begin{tabular}{cccc}
\hline Sample & Dish $(\mathrm{g})$ & Filter + Sample $(\mathrm{g})$ & Dish + Sample $(\mathrm{g})$ \\
\hline Q23 & 8.102 & 0.088 & 8.190 \\
R19 & 8.005 & 0.084 & 8.089 \\
S42 & 7.921 & 0.088 & 8.009 \\
S64 & 7.852 & 0.082 & 7.934 \\
\hline
\end{tabular}

constructing the steam generators are $\mathrm{Fe}, \mathrm{Ni}$, and $\mathrm{Zr}$, it seems natural that they are coincided each other. Fe and $\mathrm{Ni}$, which are the main elements of corrosion products, account for approximately $60 \%$ of elements and the rest of elements were $\mathrm{Zr}$, and $\mathrm{B}$, in descending order.

The contents of zinc in the nuclear fuel crud, after the zinc injection commenced, dropped to being in the range of approximately $1 \%-2 \% \mathrm{wt} \%$, except for the sample S42 (before), which was collected before the zinc injection. This shows similar results to the range of $1 \%-3 \%$ $\mathrm{wt} \%$ of zinc contents in the amount of crud reported for the nuclear power plants in the USA where zinc injection was implemented [17]. It is thought that S42 (before) showed abnormal figures because the quantity of samples collected was not sufficient. According to the crud analysis data implemented in nuclear plants in Korea, it

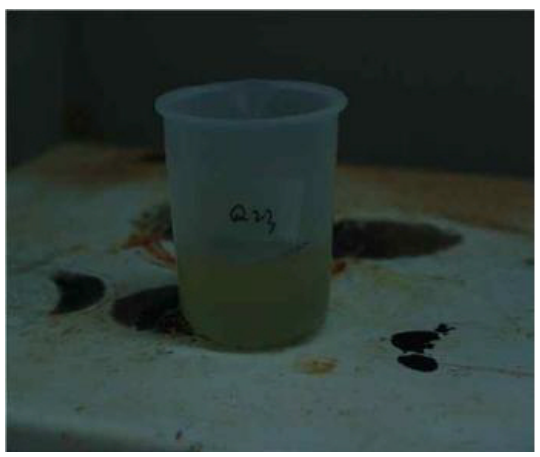

Figure 8. Sample and filter dissolution.

Table 3. Weights of dried radioactive crud samples after zinc injection.

\begin{tabular}{cccc}
\hline Sample & Dish (g) & Filter + Sample (g) & Dish + Sample (g) \\
\hline Q23 & 8.309 & 0.074 & 8.383 \\
R19 & 7.803 & 0.077 & 7.879 \\
S42 & 7.832 & 0.079 & 7.911 \\
S64 & 8.173 & 0.077 & 8.250 \\
\hline
\end{tabular}

Table 4. Comparison of the constituent element ratio before/ after zinc injection (Q23).

\begin{tabular}{ccc}
\hline \multirow{2}{*}{ Elements } & \multicolumn{2}{c}{ Measured Constituent Element Ratio (\%) } \\
\cline { 2 - 3 } & Before Zinc Injection & After Zinc Injection \\
\hline $\mathrm{B}$ & 2.6 & 10.8 \\
$\mathrm{Cr}$ & 6.4 & 9.8 \\
$\mathrm{Fe}$ & 25.1 & 40.6 \\
$\mathrm{Ni}$ & 32.2 & 22.5 \\
$\mathrm{Mn}$ & 0.3 & - \\
$\mathrm{Zn}$ & 0.4 & 0.9 \\
$\mathrm{Zr}$ & 3.3 & 15.3 \\
\hline
\end{tabular}


Table 5. Comparison of the constituent element ratio before/ after zinc injection (R19).

\begin{tabular}{ccc}
\hline \multirow{2}{*}{ Elements } & \multicolumn{2}{c}{ Measured Constituent Element Ratio (\%) } \\
\cline { 2 - 3 } & Year 2009 & Year 2011 \\
\hline $\mathrm{B}$ & 9.0 & 9.3 \\
$\mathrm{Cr}$ & 4.5 & 8.0 \\
$\mathrm{Fe}$ & 27.8 & 28.4 \\
$\mathrm{Ni}$ & 29.0 & 23.4 \\
$\mathrm{Mn}$ & 0.8 & - \\
$\mathrm{Zn}$ & 0.2 & 1.4 \\
$\mathrm{Zr}$ & 28.7 & 28.9 \\
\hline
\end{tabular}

Table 6. Comparison of the constituent element ratio before/ after zinc injection (S42).

\begin{tabular}{ccc}
\hline \multirow{2}{*}{ Elements } & \multicolumn{2}{c}{ Measured Constituent Element Ratio (\%) } \\
\cline { 2 - 3 } & Year 2009 & Year 2011 \\
\hline $\mathrm{B}$ & 15.5 & 12.3 \\
$\mathrm{Cr}$ & 2.9 & 8.1 \\
$\mathrm{Fe}$ & 34.6 & 41.1 \\
$\mathrm{Ni}$ & 16.7 & 18.7 \\
$\mathrm{Mn}$ & 0.4 & 0.2 \\
$\mathrm{Zn}$ & 5.3 & 1.3 \\
$\mathrm{Zr}$ & 24.6 & 17.2 \\
\hline
\end{tabular}

Table 7. Comparison of the constituent element ratio before/after zinc injection (S64).

\begin{tabular}{ccc}
\hline \multirow{2}{*}{ Elements } & \multicolumn{2}{c}{ Measured Constituent Element Ratio (\%) } \\
\cline { 2 - 3 } & Year 2009 & Year 2011 \\
\hline $\mathrm{B}$ & 30.8 & 1.9 \\
$\mathrm{Cr}$ & 3.5 & 4.9 \\
$\mathrm{Fe}$ & 23.4 & 32.7 \\
$\mathrm{Ni}$ & 16.6 & 28.5 \\
$\mathrm{Mn}$ & 0.4 & 0.2 \\
$\mathrm{Zn}$ & 0.6 & 1.1 \\
$\mathrm{Zr}$ & 24.8 & 30.1 \\
\hline
\end{tabular}

has been reported that the element of zinc in crud could exist in the form of $\mathrm{ZnO}$ particles, whose magnitude is within several ten $\mu \mathrm{m}$ [18]. If one or two of these particles are included in the crud samples collected, they could distort the contents of the zinc with quite fair possibilities. The element $\mathrm{Zr}$, which exists in large contents in crud, comes from the fuel claddings. It is thought that the corrosion oxide layers formed on fuel rod claddings are destroyed and thus, $\mathrm{Zr}$ is detected. Such high concentrations of $\mathrm{Zr}$ have been reported for other nuclear power plants where ultrasonic cleaning was implemented [19].

Figure 9 shows the results of the constituent element ratio analysis before and after zinc injection for all of the filters that were collected for crud samples. It was found that the content of the element $\mathrm{Zn}$ in the reactor coolant increased by $0.7 \%$ point due to zinc injections. Especially, the atomic ratio of $\mathrm{Ni} / \mathrm{Fe}$ that was measured before the zinc injection was 1.12 , whereas the ratio measured in 2011 was decreased to an average of 0.69 . The boron content in the oxide layer before the zinc injection was $30.8 \%$, which decreased to $7.8 \%$ after the zinc injection.

\subsection{Radioactivity Analysis}

Some of the dissolved samples were taken and were diluted and analyzed using the HPGe gamma nuclide analyzer (HPGe GEM 30185-P, EG\&G ORTEC).

The dose rates of all the samples were measured and then the radioactive nuclides contained in the crud collection filters were measured together with their radioactivity using the gamma ray detector. The results are as follows:

Figure 10 shows the results of the gamma nuclide analysis of the filters, which collected nuclear fuel corrosion products before zinc injection. From this figure, it can be found that the concentration of Co-58, which is one of the main radiation sources in the reactor coolant of Ulchin 1, was approximately ten times higher than that of Co-60. Co-58 is an activation product of $\mathrm{Ni}$, which comes from the Ni alloy used for the steam generator tubes, and is one of the main radiation sources in light water reactor power plants. Therefore, the technology of zinc injection, which is one of the technologies that can be used to reduce Co-58, is expected to play an effective role in radioactive dose reduction.

Figure 10 shows the overall results of the radioactivity concentration analysis before/after zinc injection. As shown in Figure 10, when the concentrations of Co$58 / 60$ of the collection filters before and after zinc injection are compared, the dose rate of $\mathrm{Co}-58$ for the four samples changes from $1.41 \mathrm{E}+08 \mathrm{~Bq} / \mathrm{g}$ before zinc injection to $6.32 \mathrm{E}+06 \mathrm{~Bq} / \mathrm{g}$ after it, resulting in a $1 / 22$ times reduction. But for Co-60, the change is from $1.20 \mathrm{E}$ $+07 \mathrm{~Bq} / \mathrm{g}$ before zinc injection to $1.58 \mathrm{E}+07 \mathrm{~Bq} / \mathrm{g}$ after it, meaning that there is not a remarkable change.

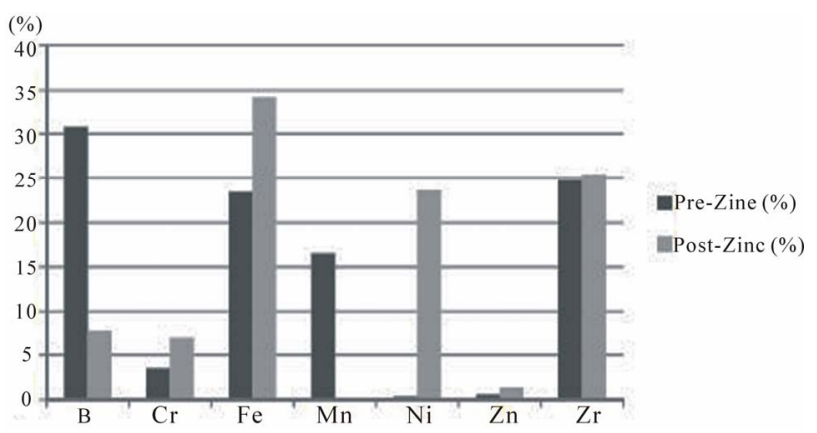

Figure 9. Change of contents for different constituents before /after zinc injection. 


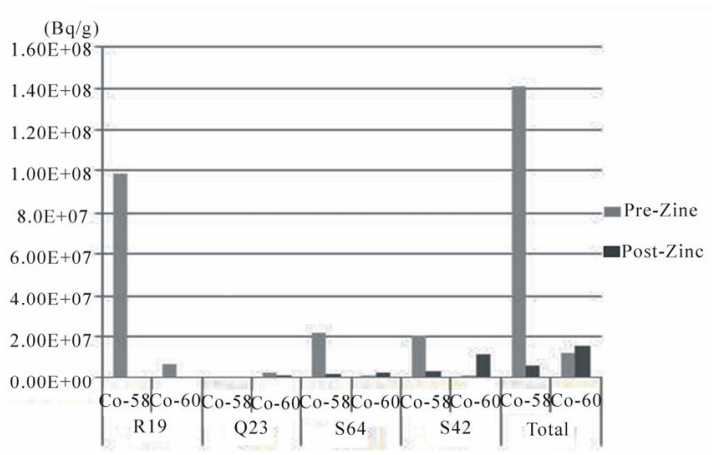

Figure 10. Analysis of radioactivity concentration before/ after zinc injection.

The changes in concentration of Co-58/60 due to zinc injection can be interpreted as depending on the cause of birth of Co-58/60. Co-58 is generated by activation of $\mathrm{Ni}$ and when zinc injection is done, $\mathrm{Ni}$ is effectively removed and thus the additional generation of Co-58 is also reduced [20-24]. Furthermore, the half-life period of Co-58 is only 70 days, which means that the concentration of Co-58 before zinc injection was naturally reduced along with the decay of the isotope. On the contrary, in the case of Co-60, which is generated by the activation of $\mathrm{Co}$, the concentration of Co before zinc injection was very low from the beginning and thus the eliminated quantity was also negligible. On top of that, it is thought that since the half-life period of Co-60 is 5.27 years, which means that the concentration of Co-60 existing in the oxide layers has virtually not changed.

\section{DISCUSSION}

Figures 11 and 12 show the oxide layers before/after zinc injection. As shown in the figures, the substitution reaction, as shown below, takes place at the oxide layers of nuclear fuels due to zinc injection.

Zinc substitution at the oxide layers of fuel claddings

$$
\begin{aligned}
& \mathrm{NiO}+\mathrm{Zn}^{2+} \rightarrow \mathrm{ZnO}+\mathrm{Ni}^{2+} \\
& \mathrm{NiFe}_{2} \mathrm{O}_{4}+\mathrm{Zn}^{2+} \rightarrow \mathrm{ZnFe}_{2} \mathrm{O}_{4}+\mathrm{Ni}^{2+} .
\end{aligned}
$$

As shown in Figure 11, regarding the oxide layers on nuclear fuels, the corrosion products are thickly deposited in the upper area of the fuel rods since the temperature is higher and the thermal load is heavy. The nuclear fuel oxide layers are porous, as shown in Figure 13. The boiling phenomena in the pores cause a concentration of boron dissolved in reactor coolant.

The function of boron, which is a chemical used for reactor power control, is to lower the power of nuclear fuels by absorbing neutrons. If boron is concentrated in the upper area of fuel rods, it reduces the power output at the upper area, which eventually in effect hinders normal plant operation. As shown in Figure 11, there existed at
Ulchin 1, a large quantity of boron before the zinc injection. However, after the zinc injection, as shown in Figure 12, the oxide layers were reformed and the voids in oxide layers were reduced, and thus, as shown in Figure 11, the content of boron in the oxide layers was also remarkably reduced. Through such processes, the phenomenon of abnormal output unbalances of nuclear fuels due to local boron concentration was also reduced. Figures 12 and 14 show the configuration of oxide layers after zinc injection. As such, they also show thin and stable oxide layers as having fewer voids and that are formed due to oxide layers reformation according to zinc injection.

The deposits of the oxide layers of the nuclear fuels before a zinc injection consist mainly of nickel oxide $(\mathrm{NiO})$ and nickel ferrite $\left(\mathrm{Ni}_{\mathrm{x}} \mathrm{Fe}_{3-\mathrm{x}} \mathrm{O}_{4}\right)$ (Figure 11). If the ratio of nickel oxide and nickel ferrite is $1: 1$, the ratio of $\mathrm{Ni} / \mathrm{Fe}$, according to analysis of chemical constituents, is approximately 1.1 . The ratio of $\mathrm{Ni} / \mathrm{Fe}$ in the crud of nuclear fuel before zinc injection was, when precisely examined, 1.12. This means that the nickel oxide content was slightly higher than nickel ferrite. This is generally a normal phenomenon considering it has been reported that at the core of the long fuel cycle that has a high burn-up, a relatively high value of the content of nickel oxide in crud. Additionally, through an analysis of the $\mathrm{Ni} / \mathrm{Fe}$ contents ratio, it can be observed that in the nuclear fuel

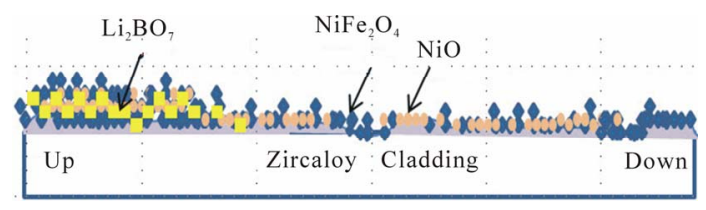

Figure 11. Schematic diagram of the deposition of fuel oxides before zinc injection.

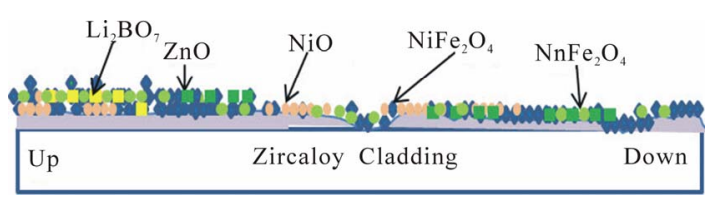

Figure 12. Schematic diagram of the deposition of fuel oxides after zinc injection.

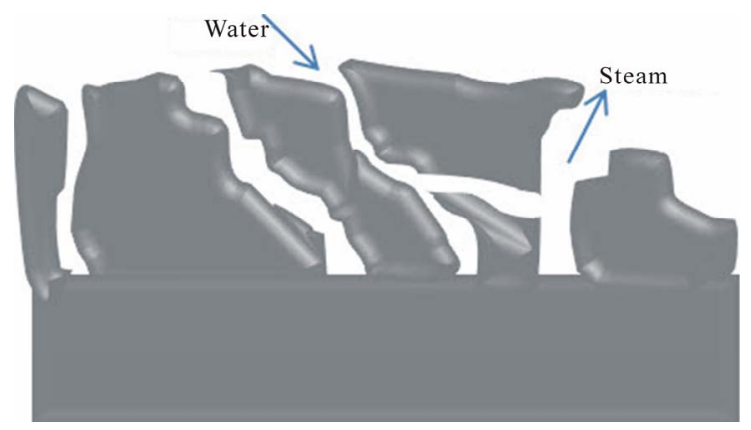

Figure 13. Nuclear fuel cladding oxide layers. 
oxides, not only nickel ferrite $\left(\mathrm{NiFe}_{2} \mathrm{O}_{4}\right)$, but also nickel oxides, such as nickel oxide ( $\mathrm{NiO})$, does exist. It was found that when the $\mathrm{Ni} / \mathrm{Fe}$ constituent ratio measured was converted to a mass ratio, the existence ratio of $\mathrm{NiFe}_{2} \mathrm{O}_{4}$ and $\mathrm{NiO}$ was approximately 1:1.2. However, after zinc injection, the $\mathrm{Ni} / \mathrm{Fe}$ constituent ratio drastically fell to 0.69 compared to before. Generally, for nuclear fuel oxide layers, if zinc is injected, it shows active substitution effects where the doubly charged zinc ions substitute such elements as nickel, iron, cobalt, etc., which can be doubly charged.

Compared with the previous state where $\mathrm{NiO}$ and $\mathrm{NiFe}_{2} \mathrm{O}_{4}$ existed with the ratio of 1.2:1, as shown in Figure 11, it can be observed that some of the $\mathrm{NiO}$ and $\mathrm{NiFe}_{2} \mathrm{O}_{4}$ have been substituted with $\mathrm{ZnO}$ and $\mathrm{ZnFe}_{2} \mathrm{O}_{4}$ due to the substitution effect of zinc. Additionally, through the analysis of the $\mathrm{Ni} / \mathrm{Fe}$ ratio for the said nuclear fuel crud constituents, it was observed that the amount of nickel was reduced by $38 \%$. Nickel is a production source in that when it is activated, it is changed to radioactive cobalt (Co-58). The $\mathrm{Co}-58$ that is generated is one of the factors that increases the dose rates of nuclear power plants. However, it was observed that when the amount of nickel was reduced, the concentration of Co-58 was also reduced. It has been reported that if activation takes place in the reactor core, the ratio of daughter nuclides and mother nuclides (the relationship between $\mathrm{Co}-58$ and $\mathrm{Ni}$ ) shows quite a constant value. It is observed that such a variation of concentrations is generally a linear relationship [1]. Figure 15 shows the linear relationship between the radioactivity of Co-58 in a crud sample and the concentration of $\mathrm{Ni}$ in the same crud for Ulchin 1.

By using these results, the zinc substitution reaction in the oxide layers of nuclear fuel claddings before/after zinc injection has been reviewed. It has been observed that the zinc substitution reactions were actively taking place in the system oxide layers according to the zinc injection, which enabled an efficient execution of nickel elution and elimination. Additionally, it was observed that stable zinc oxide layers were formed, which greatly contributed to the reduction of system dose rate and corrosion.

\section{CONCLUSIONS}

To examine the substitution effects in the nuclear fuel-

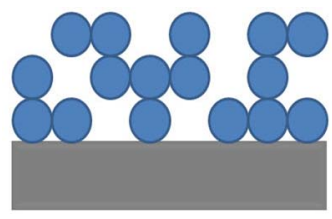

Before Zinc Injection

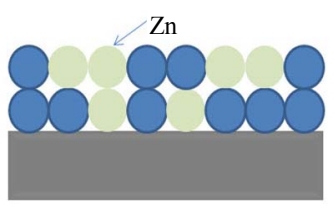

After Zinc Injection
Figure 14. Changes in oxide layers before/after zinc injection.

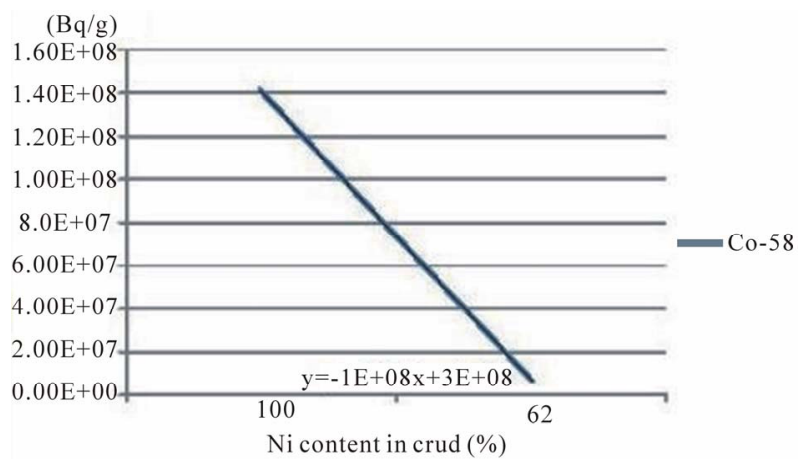

Figure 15. Variation of Co-58 for different Ni content in crud.

oxide layers following the zinc injections at Ulchin 1, samples of the corrosion products of nuclear fuel assemblies were taken and through radioactivity and chemical constituent analyses, the effect of zinc substitution was studied.

The fuel assemblies, which were burned up to the maximum in the 2nd fuel cycle, were selected and four of them were taken and a collection of crud was implemented. The collected crud was transported to a special shielding body that was completely dissolved by sample preprocessing and, using the dissolved samples, the measurement of dose rates and analysis of chemical constituents were made.

As for the dose rate measurement, the measurement and review for Co-58/60, which is one of the key nuclides that contributes the most to nuclear power plant dose rates, were made. By comparing the dose rates before and after the zinc injection, it was observed that the dose rate of Co-58 after the zinc injection was reduced to approximately $1 / 22$ times that before the zinc injection. Not a big change in the dose rate for Co-60 was observed. This could be interpreted that due to effective Ni elimination which is result from zinc injection, the generation of $\mathrm{Co}-58$, which is an activation product of $\mathrm{Ni}$, was relatively reduced.

The $\mathrm{Ni} / \mathrm{Fe}$ constituent ratio, which was obtained through a chemical constituent analysis, was reduced from 1.12 to 0.69 . Through this observation, it could be concluded that $\mathrm{ZnO}$ and $\mathrm{ZnFe}_{2} \mathrm{O}_{4}$ effectively substituted $\mathrm{NiO}$ and $\mathrm{NiFe}_{2} \mathrm{O}_{4}$, due to zinc injection.

In summary, it has been concluded that with the zinc injection being utilized, the effect of oxide layer substitution was actively exerted and through this the oxide layers of fuel claddings were reformed to stable states and that this greatly contributed to the reduction of dose rates and corrosion.

\section{REFERENCES}

[1] Maeng, W.Y., et al. (2009) Nuclear chemistry guidance, KAERI, Taejon. 
[2] EPRI (2011) PWR dose reduction efforts at Exelon. Proceedings of the August 2011 EPRI PWR Primary Zinc Addition Workshop, Palo Alto, August 2011, 2-9.

[3] EPRI (2011) EPRI chemistry update. Palo Alto, August 2011, 1022547.

[4] EPRI (2005) Mechanisms of zinc interaction with oxide films in high-temperature water. Proceedings of the $\mathrm{Au}$ gust 2004 EPRI PWR Primary Zinc Addition Workshop, Toronto, 19-20 August, 2004, 2-5.

[5] Byers, A. (2005) Zinc and CRUD, how they interact. EPRI Fuel Reliability Program WG1 Meeting, Las Vegas, 1 September 2005, 2-6.

[6] EPRI (2002) Effects of zinc addition on mitigation of PWSCC of alloy 600. Palo Alto, 1003522.

[7] EPRI (1995) PWR primary water chemistry guidelines. Revision 3, Appendix A, Palo Alto, TR-105714.

[8] Beverskog, B. (2004) The role of Zinc in LWRs. International Conference: Water Chemistry of Nuclear Reactor Systems, San Francisco, 11-14 October 2004, 2-12.

[9] Choi, I.-K., et al. (2006) Development of analytical techniques for characteristics of CRUD, KAERI, Taejon, CR-270.

[10] Yeon, J.-W., Choi, I.-K., Park, K.-K., Kwon, H.-M. and Song, K. (2010) Chemical analysis of fuel crud obtained from Korean nuclear power plants. Journal of Nuclear Material, 404, 160-164. doi:10.1016/j.jnucmat.2010.07.024

[11] McClure, D.S. (1957) The distribution of transition metal cations in spinels. Journal of the Physical Chemistry of Solids, 3, 311. doi:10.1016/0022-3697(57)90034-3

[12] EPRI (1986) The solubility of simulated PWR primary circuit corrosion products. Palo Alto, NP-4248.
[13] EPRI (2006) Pressurized water reactor primary water zinc application guidelines. Palo Alto, 1013420.

[14] Tigeras, A., Debec, G., Jeannin, B. and Rocher, A. (2006) EDF zinc injection: Analysis of power reduction impact on the chemistry and radiochemistry parameters. Proceedings of International Conference on Water Chemistry in Nuclear Reactor Systems, Jeju, 23-26 October 2006, 1-2.

[15] Lister, D. (1993) Activity transport and corrosion processes in PWRs. Nuclear Energy, 32, 103-114.

[16] (2006) Zinc acetate dihydrate, depleted in isotope Zn-64. Material Safety Data Sheet of DZA, ISOFLEX, San Francisco.

[17] EPRI (2000) Evaluation of zinc addition in cycle 13 at Farley Unit 2. Palo Alto, TR-1000251.

[18] EPRI (1996) Evaluation of zinc addition to the primary coolant of PWRs. Palo Alto, TR-106358-V1.

[19] Ultrasonic Fuel Cleaning Efficacy Campaign Results at Callaway. CA:2002, TR-1003229.

[20] Moon, J.H., Chung, H.H., Sung, K.W. and Kim, U.C. (2005) Nuclear engineering and technology. 37, 375-384.

[21] (1977) Chart of nuclides. 12th Edition, General Electric Company, Schenectady.

[22] EPRI (2003) PWR operating experience with zinc addition and the impact on plant radiation fields. Palo Alto, 1003389.

[23] EPRI (1989) Corrosion product release in light water reactors. Palo Alto, EPRI NP-6512.

[24] KAERI (2005) The evaluation for zinc injection into primary water in Korea. Taejon. 